\title{
OpenNotes Project "levels the playing field" between doctors and patients
}

Previously published at www.cmaj.ca

$\mathrm{T}$ hink of it as online access to the good, the bad and the sometimes blunt things that doctors write about patients.

In a test to measure whether sharing doctor's notes affects quality of primary care, roughly 25000 patients at the Beth Israel Deaconess Medical Center in Boston, Massachusetts, a rural hospital in Pennsylvania and a county hospital in Washington, are being given full online access to their physicians' notes for the course of one year (www.myopennotes.org).

The OpenNotes Project aims to improve communication and transparency between doctors and patients, many of whom don't even realize notes are being taken, says Dr. Tom Delbanco, a lead investigator of the study. "We share these notes with consultants, insurers and people who evaluate quality of care, but almost never with the patient. I think providers feel these are their own records, rather than their patients', so in quiet ways, perhaps unconsciously, they build up obstacles to patients gaining access to them."

As in Canada, American patients have a legal right to review their doctors' notes as part of their medical records. However, those who wish to gain access to the files often face prohibitive printing or copying fees, lengthy processes and delays, as well as all manner of bureaucratic red tape, says Delbanco. "At the same time, it's been shown patients remember very little of what goes on in the examining room."

A person's capacity to listen clearly is compromised when they're sick or stressed, says Michael Meltsner, a patient participating in the study and a law professor at the Northeastern University School of Law in Boston.

"It's like amnesia sets in. I once made a visit to a different doctor with my wife, and later on she was telling

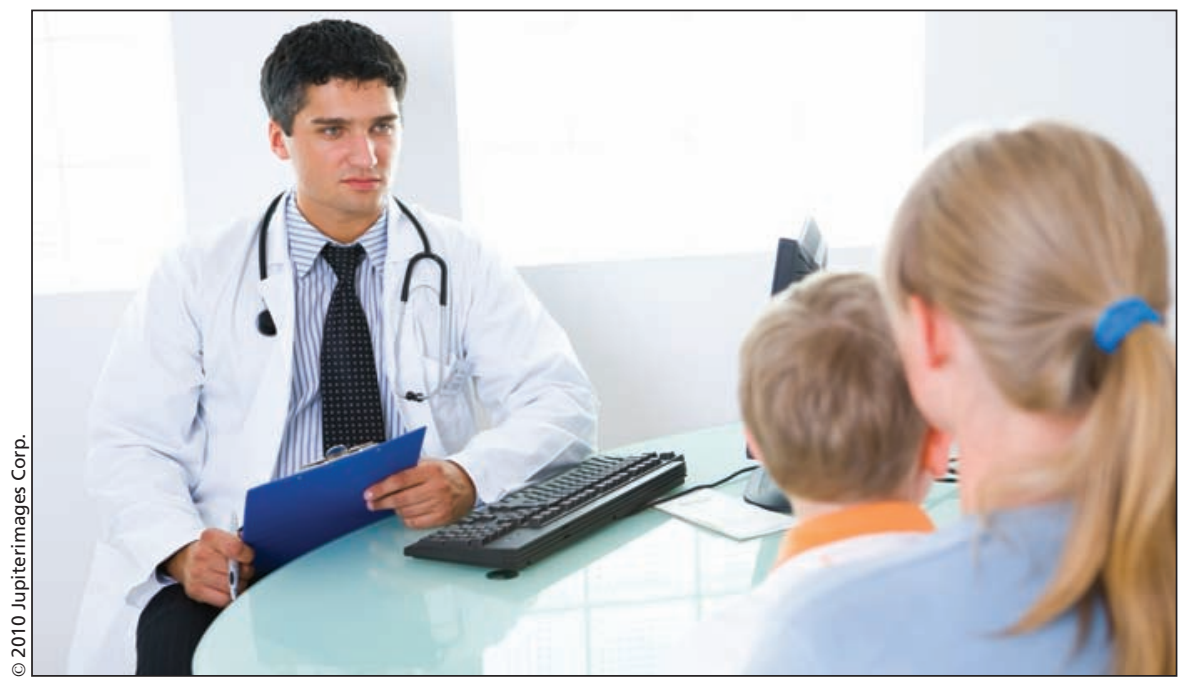

The 12-month OpenNotes Project involves more than 100 participating primary care physicians, who post their notes to secure websites for their patients to access.

me all these things that had come up in our conversation, and I had completely screened them out," he says.

Not having a reliable record of what goes on in the doctor's office "inhibits the kinds of discussions that lead to clarification and support, not only between a patient and their doctor, but also between a patient and their family," Meltsner adds.

As part of the 12-month study, more than 100 participating primary care physicians will post their notes to secure websites for their patients to access. The patients will be reminded by email to review the notes before and after each visit to their doctor.

Meanwhile, researchers will survey both participating patients and doctors to assess the impact of sharing the notes on quality of care, physician workflow and patient engagement.

"Ultimately, we're asking a very simple question: At the end of the study, do the doctors and patients want this to continue?" explains Delbanco. "I suspect having access to these notes will make patients more actively involved in their care, better educated about their illnesses, and better able to detect and prevent medical errors."

Reading the notes has been "rewarding and refreshing," says Meltsner. "This is a chance to level the playing field. The doctor who shares his notes is not a kind of unmoved mover, a hewho-must-be-obeyed. He's someone you can talk to and question."

But doctors have been less enthusiastic, Delbanco says. "Of those we asked to participate in the project, the majority politely declined. I think their biggest fear is that this will slow things down, that busy doctors will be made busier answering questions about what they wrote."

But study participant Jeanne Hallissey says her doctor's notes have cleared up more questions than they've raised. "I find the notes help me to understand what is going on and answer a lot of questions I may not think of asking when I go for a follow up appointment."

Delbanco says physicians also typically fear that their patients may be confused or frightened by what they read in the notes.

Written in medical jargon and shorthand, physicians' notes often contain 
personal speculations about patients and possible diagnoses that may be taken out of context. Some abbreviations, such as using "SOB" to stand for "shortness of breath," could come across as a slur to the untrained eye.

"I find myself writing my notes somewhat differently, but not very differently," Delbanco says. "I use fewer technical words, I'll add some educational material as I go and I'll think more consciously of what the patient will experience reading the note."

Putting more thought into a note doesn't take more time, he adds. "I find it doesn't take one second longer. It's just a different way of doing business."
Patients are more resourceful than their doctors may suspect, Hallissey says. "If I read some medical terminology I don't understand, I go on Google or some search engine and find the definition. I know how busy physicians are today and time is important to them."

Another advantage for patients, Meltsner says, is that some doctors can be clearer in their notes than they are face to face. Doctor's concerns over political correctness can lead them to be less than candid in conversations (CMAJ 2010. DOI:10.1503 /cmaj.109-3308).

But the clarity that doctors' notes can offer may be a double-edged sword when it comes to medical errors. Some physicians are concerned that opening their notes to patients may in turn open themselves to malpractice suits, says Delbanco.

Meltsner, though, argues that transparency is just as likely to quell litigation as to provoke it. "The notes could reveal just as many things the doctor did right that the patient may not have known about," he says.

It's expected that preliminary findings of the study will be published early in 2011. The project will conclude next summer. - Lauren Vogel, CMAJ

\section{Obama's health law at six months: survival is not assured}

\section{Previously published at www.cmaj.ca}

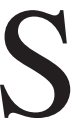
ix months after President Barack Obama's landmark health care law, free preventive care is taking effect for millions more Americans, children have new insurance protections and seniors are getting more help for their drug bills, all down payments on an unfolding and historic transformation of the system.

So where's the love?

The hard-won reforms remain a hard sell for the public. They are proving to be fodder, too, for Republicans who have "Obamacare" in their crosshairs heading into fall elections that could change the balance of power in Washington - and the course of health care yet again.

The benefits of the new law are taking effect in myriad ways, some more visible than others. As of Sept. 23, insurance companies were no longer allowed to set lifetime limits on benefits in new or renewing plans. They were also prohibited from denying coverage to sick children, another widely despised practice. They also had to let children younger than 26 years of age remain on their parents' employerbased health plans in most cases.

Preventive treatment also got a boost at the same time. An estimated 41 million people gained free access to a range of preventive services from
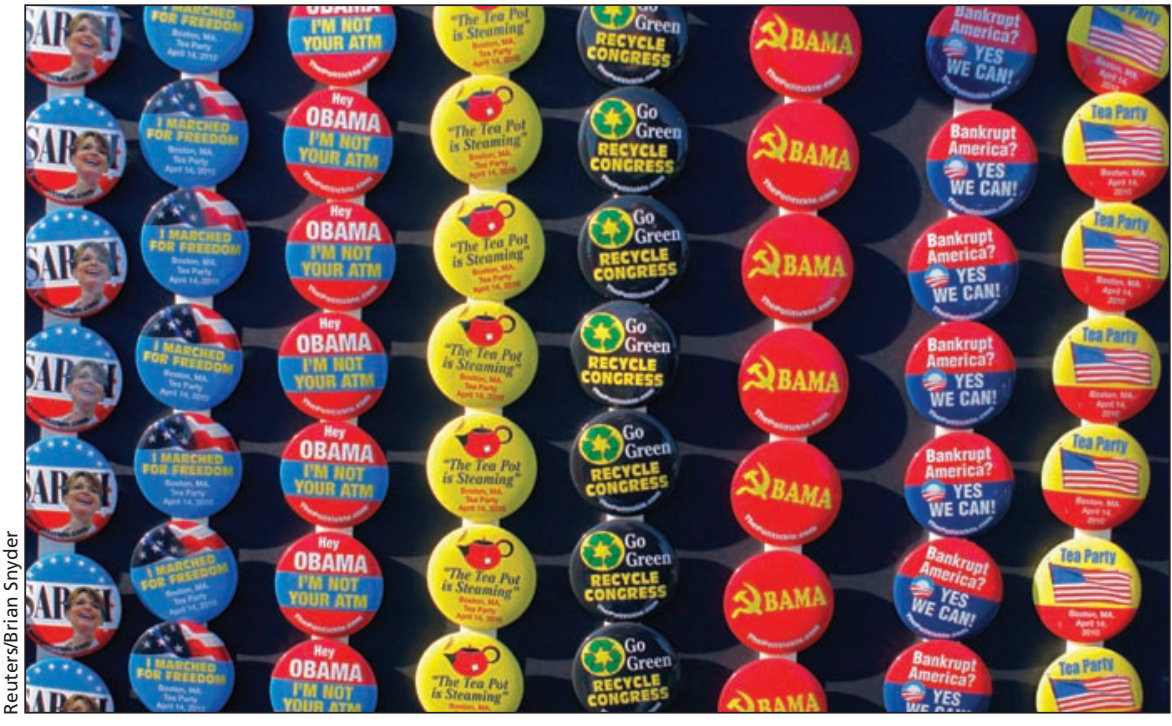

An array of forces hope to undermine United States President Barack Obama's Patient Protection and Affordable Care Act.

weight and smoking cessation counseling to vaccines, well-baby care and routine screenings for cancer and other disease. Federal money is pouring into community health centers, electronic record-keeping in doctors' offices, and scholarships and debt relief for health professionals in needy areas.

Few dispute the value of such steps. The problem remains as it has always been: a suspicion of growing federal power in health care and people's lives.

The reforms are anchored by a looming reality that splits the country:
Health insurance will become mandatory under the plan in 2014 (enforced by the much-unloved Internal Revenue Service). People will need to buy it just as drivers need auto insurance. And only with universal coverage - the tens of millions more paying customers it will bring - can the private insurance market live under the new rules and can taxpayers sustain an overhaul costing an estimated US\$1 trillion over a decade.

It's that mandate Republicans have sworn to defeat. 